\title{
The history and sociology of computer science and technology : 26 references.
}

\author{
Camille Akmut
}

January 12,2020

Abstract : Continuation, and possibly end, of a "peer review" started long ago. 


\section{ADMINISTRATIVE DOCUMENTS}

[1] Abelson, Hal et al.. 2013. Report to the President. MIT and the Prosecution of Aaron Swartz.

Description : Part I, pp. 16-28, is a detailed account including many technical and human details. The program written by Swartz was not described (and the few allusions to it, e.g. cookie faking, appear to be wrong), but we have done so elsewhere. Pp. 31-33 provide additional information as explanation (various antecedents).

"Before Aaron Swartz's suicide, the MIT community paid scant attention to the matter (...). Few students, faculty, or alumni expressed concerns to the administration." (p. 14)

(The flower of U.S.-American education and intelligentsia! An exciting and vibrant 'community of minds', no doubt...)

\section{BOOKS}

[2] Wexelblat, Richard (ed.). 1981. History of Programming Languages. ACM.

Description : Sebasta (below) calls it "Perhaps the most important source of historical information about the development of early programming languages".

[3] Lessig, Lawrence. 2004. Free Culture. Penguin.

Description : Lessig deploys a vast culture, legal history and beyond. "the Licensing Act of 1662 ... gave publishers a monopoly over publishing, as a way to make it easier for the Crown to control what was published." Jack Valenti, mentioned by Swartz in a funny blog post, is named multiple times. In the preface, he notes : " as I reread Stallman's own work ... I realize that all of the theoretical insights I develop here are insights Stallman described decades ago.", naming "especially the essays in Free Software, Free Society".

[4] Darnton, Robert. 1985. The Literary Underground of the Old Regime. Harvard University Press.

Description : I'm pretty sure this is the material that Darnton referenced (among possibly other publications) when he was interviewed for Steal this film. (Context : parallels between the "pirates" of the printing press and so-called "pirates" of our age.) 


\section{ARTICLES}

[5] Coleman, Gabriella. 2004. "The Political Agnosticism of Free and Open Source Software and the Inadvertent Politics of Contrast" Anthropological Quarterly 77(3) : 507-519.

Description : a monumental error in scholarship. To be clear, she denies them neither political views nor motives, her argument is complex : "One might suspect FOSS of having a deliberate political agenda, but when asked, FOSS developers invariably offer a firm and unambiguous "no"." It is the relationships around beliefs and practices that preoccupy this researcher. But, rarely has anyone been more wrong than Gabriella Coleman when writing of "hacker aesthetic distaste for politics"; obviously influenced by Levy. She does not distinguish enough between groups, resulting in a sociology that is more philosophy than social science, and concepts as "big as mountains" (as Bourdieu had written of Hegel) - "large ideas" she calls them, but this can only rarely be a compliment. Meanwhile Richard Stallman openly supports Bernie Sanders, and about a thousand other causes, a certain "open source" evangelist is a well-known gun loving, Libertarian fanatic, and Jamie Zawinski spends his days writing blog posts on e.g. Uber and Saudi Arabia... "Political agnosticism"? Jesus Christ.

[6] Ochigame, Rodrigo. 2019. "The Invention of "Ethical AI". How Big Tech Manipulates Academia to Avoid Regulation" The Intercept, 20/12.

Description : "[These academics] lent credibility to the idea that big tech could police its own use of artificial intelligence at a time when the industry faced increasing criticism and calls for legal regulation."

\section{[7] McCarthy, John. "History of LISP". In : Wexelblat 1981.}

Description : when asked who gave him the permission to work on LISP, McCarthy responded : "No one" (Communist during his best years, later turned conservative.)

[8] Akmut, Camille. 2019. "Aaron Swartz's JSTOR code. Further research notes."

Description : here I described keepgrabbing.py, the program used in the events described in [1] (where the emphasis was on networks, system administration policies and physical aspects), almost line by line. Additions to come later.

\section{TEXTBOOKS}

Anachronistic historians will still not understand the point of this section, so they may as well best skip it. 
[9] Harvey, Brian and Wright, Matthew. 1999. Simply Scheme. 2nd ed.. MIT Press.

Description : from a historical perspective, the foreword by Hal Abelson (who quoted Perlis : "Algol (...) belongs in a plumber's union" — whatever that means) and preface by the authors are of particular interest; being representative of a certain epoch. The typical MIT/Hacker/LISPers-Schemers critique of Pascal, etc.. (See also the relevant entries in The Hacker's Dictionary e.g. "bondage and discipline language(s)".)

[10] Sebasta, Robert. 2016. Concepts of programming languages. 11th ed.. Pearson.

Description : chapter 2 is a short history of programming languages in fifty pages, from Plankalkul to PHP... Of the former we are told : "Zuse's manuscript contained programs of far greater complexity than any written prior to 1945." The greatest language that never was... (One more genealogy at the beginning of this section.)

\section{METHODOLOGY}

\section{[11] Annales}

Description : legendary journal of legendary historians. (We produced a loose translation of Febvre's 1948 "On a certain style of history that is not ours", rather faithful to the spirit than the letter. He was not very courageous during the War, but at least showed integrity in his research, and that is much more than can be said of many modern "scholars"...)

\section{POPULAR CULTURE}

"Americans [not only] tend to look down upon this form of culture. That's an unattractive characteristic of ours." (Lessig in Free Culture, writing about manga in particular)

[12] Clements, Jonathan and McCarthy, Helen. The anime encyclopedia. Stone Bridge Press.

Description : useful to anyone interested in the "inner lives" of computer scientists and technologists, in the tradition of Bachelard. (Look up the other books by these authors : Anime: A history, A brief history of manga,...)

[13] Galbraith, Patrick. The otaku encyclopedia.

[14] Beck, Jerry. 2005. The animated movie guide. Chicago Review Press. 
Description : "Every animated feature released in the United States since 1926".

[15] Otomo, Katsuhiro (manga writer, director). 1988. Akira.

Description : milestone in Japanese animation, all authors seem to agree. "the first Japanese anime movie to break out of small overseas science-fiction fan clubs and reach an art house and mainstream audience" writes Galbraith (who calls it "arguably the greatest anime of all time"), " the most expensive animated film produced in Japan at its release" notes Beck, while Clements and McCarthy argue "almost singlehandedly responsible for the early 1990s boom in anime in the English language." Clements and McCarthy propose further the convincing thesis : "Akira owes less to an alleged "cyberpunk" sensibility than it does to the young Otomo's perspective on 1960s counterculture".

Few other filmmakers can be said to have explored the themes around the new body and the new mind (called "shell", "ghost") as far as Oshii, and with as much talent, and as many insights as he did. Based on Shirow's work, which he often transcends.

\section{[16] Oshii, Mamoru. 1995. Ghost in the Shell.}

Description : The next big step for science-fiction anime films after Akira, with which it shares important characteristics (high budget, production quality, and brought anime to a new wave of fans). In turn, Clements/McCarthy tell us of it : "one of the few that could reasonably claim to be a true cyberpunk film." Beck notes accurately : "Oshii changed the setting from a futuristic Tokyo to a $[n]$... anonymous Asiatic metropolis based more upon Hong Kong."

\section{[16] Oshii, Mamoru. 2004. Ghost in the Shell 2.}

Description : This follow-up movie, far from a commercial gimmick or exploitation, is actually a far more intellectual version (a collection of eclectic literaryphilosophical references, presumably gathered in the 10 years separating the two films, regularly give rise to impromptu, surreal exchanges). Clements/McCarthy give this useful explanation: "Innocence draws heavily on a single chapter of the original manga ("Robot Rondo"), but while it uses characters and situations created by Masamune Shirow, it is largely the work of Mamoru Oshii."

"If our gods and hopes are nothing but scientific phenomena, then it must be said too that our love ..." (opening quote, The Future Eve)

\section{[17] Scott, Ridley. 1982. Blade Runner.}

Description : the authors cited in this section all trace back the aforementioned anime to Blade Runner. "Much of Japanese cyberpunk is influenced by Scott's 
vision of "the city" in Blade Runner, a look that was in turn partially influenced by Tokyo's futuristic neon urban landscape. (...) [Its] themes, elements, and designs ... return again and again in anime and manga such as Bubblegum Crisis, Akira, Ghost in the Shell, and many others." writes Patrick Galbraith, for instance.

[18] Villeneuve, Denis. 2017. Blade Runner 2049.

Description : an interesting, further exploration of the themes developed in the 1982 film. (Blade runners are humans - in the original - or androids - here whose task it is to terminate, i.e. "kill", older android models whose features are now considered a nuisance, undesirable or even dangerous for the status quo.)

\section{[19] Sanders, Rupert. 2017. Ghost in the Shell.}

Description : in a year or revivals, this Ghost in the Shell "live-action" version (anime fans slang for what everyone else calls simply a film...), added new interpretations, including more confusion to Shirow's basis - as almost all adaptations have done. To recap : Project 2501 is the "Puppet Master" (manga and 1995 film), Project 2571 is what led to "Major" (Motoko Kusanagi) and "Kuze" (Hideo) in this film, while 2502 is a new type of model, 'gynoid', at the center of the intrigue of the second, 2004 film...

[20] Groening, Matt. 1999-2003; 2010-2013. Futurama.

Description : in Futurama, the hardest problem of computer science had found an answer... (See the corresponding Computerphile/Numberphile video(s).)

[21] Roiland, Justin and Harmon, Dan. 2013-ongoing. Rick and Morty.

Description : referenced by Graham Hutton, J.-P. Aumasson, Jamie Zawinski... (Rick and Morty was to the 2010's what Futurama was to the 2000's.)

[22] Moore, Alan (writer) and Lloyd, David. 1982-1985 (B-W); 1988 (color). $V$ for Vendetta.

Description : influential comic book (or "graphic novel"). See The Guardian article "Alan Moore drops anarchism to champion Labour against Tory 'parasites"' $(21 / 11 / 2019)$ for more background on the author.

[23] Lang, Fritz. 1953. The big heat.

Description : one of the poster's in V's room. Cop fights injustice against all in a city filled with corruption (and "dames"...), in this film noir. (Part of Lang's so-called 'American period', which stood in stark contrast with his more complicated German past and ambiguous films like 'Metropolis', in which some recognize "Voelkish" i.e. proto-Nazi moods... Even Goebbels was impressed!) 


\section{[24] Esmail, Sam. 2015-2019. Mr. Robot.}

Description : a counter-revolutionary work. In addition to other faults, already stated elsewhere, the creators made psychology a main factor of explanation : it was all down to childhood trauma, after all! They did it, not because the world is defined by objective inequalities, and that ought be enough reason, but - hopefully you've paid good attention - their motives could be explained by psychological factors. In the future, we will be able to say that Mr. Robot was a show that gave a lot of people hope, but was unfortunately cut short after only 2 seasons. The other two we must imagine ourselves. (Trope : trans/queer people as villains.)

[25] Taniguchi, Goro. 2003-2004. Planetes.

Description : so-called "hard science fiction" (due to the attention paid to details e.g. the diapers worn by astronauts - although that is not the preferred technical term). Space exploitation, we are told, and shown, follows the same patterns as Earth exploitation : injustice and inequalities between rich and poor nations; giving rise to "bad", "villain" terrorists...

\section{[26] Amazon production. The Expanse (2015-...).}

Description : it should be clear to anyone by now, hopefully, that these 'original' Amazon or Netflix productions do carry some message, and fulfill a certain purpose (be it to offer elitist visions of space exploration, or to make capitalism more agreeable to us by passing their visions of work, or love, or sex, or adulthood for universal). A damning review appeared in Jacobin under the title "Jeff Bezos and His Billionaire Space Fantasy" (14/12/2019).

"Jeff Bezos helped save the sci-fi TV show The Expanse because he wants to promote space colonization - on capitalist terms. But ironically, the show he saved depicts a grim and brutal life for workers on Earth and beyond."

We are very far, here, from Roddenberry's paternalist, but kind-hearted visions of space... 
Dedicated to Aaron Swartz (1986-2013).

26 years, 26 references. 